\title{
Defensive changes in maize leaves induced by feeding of Mediterranean corn borer larvae
}

\author{
Rogelio Santiago ${ }^{1,4^{*}+}$ D , Ana Cao ${ }^{1,2,4 \dagger}$, Ana Butrón², Ana López-Malvar ${ }^{1,4}$, Víctor M. Rodríguez²,
} Germán V. Sandoya ${ }^{3}$ and Rosa A. Malvar ${ }^{2}$

\begin{abstract}
Background: Plants can respond to insect attack via defense mechanisms that reduce insect performance. In this study, we examined the effects of several treatments applied to two maize genotypes (one resistant, one susceptible) on the subsequent growth and survival of Sesamia nonagrioides Lef. (Mediterranean corn borer, MCB) larvae. The treatments were infestation with MCB larvae, application of MCB regurgitant upon wounding, wounding alone, or exposure to methyl jasmonate, and they were applied at the V6-V8 stage of maize development. We also monitored changes in the concentrations of compounds known to be involved in constitutive resistance, such as cell wall-bound hydroxycinnamates and benzoxazinoids.
\end{abstract}

Results: In both maize genotypes, the leaves of plants pre-infested with MCB larvae were less suitable for larval development than those from untreated plants. Application of MCB regurgitant upon wounding, and wounding itself, resulted in leaf tissues becoming less suitable for larval growth than those of pre-infested plants, suggesting that there could be herbivore-associated effector molecules that suppress some wounding responses. A single application of MCB regurgitant did not seem to mimic feeding by MCB larvae, although the results suggested that regurgitant deposited during feeding may have enhanced ferulates and diferulates synthesis in infested vs. control plants. Jasmonic acid may play a role in mediating the maize response to MCB attack, but it did not trigger hydroxycinnamate accumulation in the leaves to a level comparable to that induced by larval leaf feeding. The EP39 maize genotype showed an increase in leaf cell wall strength by increasing hemicellulose cross-linking in response to MCB attack, while induced defenses in the EP42 plants appeared to reflect a broader array of resistance mechanisms.

Conclusions: The results indicated that leaf feeding by MCB larvae can increase leaf antibiosis against MCB in two maize genotypes with contrasting levels of resistance against this borer. Also, the larval regurgitant played a positive role in eliciting a defense response. We determined the effects of the plant response on larval growth, and detected defense compounds related to borer resistance.

Keywords: Induced response, Maize antibiosis, Oral secretions, Cell wall hydroxycinnamates, DIMBOA

\footnotetext{
* Correspondence: rsantiago@uvigo.es; rsantiago@mbg.csic.es

${ }^{\dagger}$ Equal contributors

'Universidad de Vigo, Agrobiología Ambiental Calidad de Suelos \& Plantas

UVIGO, Unidad Asociada MBG CSIC, Vigo 36310, Spain

${ }^{4}$ Dept. Biología Vegetal \& Ciencias Suelo, Facultad de Biología, Campus

Lagoas Marcosende, Vigo 36310, Spain

Full list of author information is available at the end of the article
}

(c) The Author(s). 2017 Open Access This article is distributed under the terms of the Creative Commons Attribution 4.0 International License (http://creativecommons.org/licenses/by/4.0/), which permits unrestricted use, distribution, and reproduction in any medium, provided you give appropriate credit to the original author(s) and the source, provide a link to the Creative Commons license, and indicate if changes were made. The Creative Commons Public Domain Dedication waiver (http://creativecommons.org/publicdomain/zero/1.0/) applies to the data made available in this article, unless otherwise stated. 


\section{Background}

The Mediterranean corn borer (Sesamia nonagrioides Lef., $\mathrm{MCB}$ ) is the main maize pest in the Mediterranean area $[1,2]$. In Spain, the first generation of MCB larvae attack maize plants at an early stage of development and feed on leaves, and the second and further generations mainly feed on the pith [3]. Several studies have focused on identifying constitutive chemical compounds in maize that are involved in resistance to $\mathrm{MCB}$, and the best candidates are benzoxazinoids and hydroxycinnamates $[4,5]$.

Benzoxazinoids are the most extensively studied cereal phytoalexins because they play a major role in the defense of cereals against insects, fungi, bacteria, and adventitious plant species [6]. In young maize plants, benzoxazinoids, especially DIMBOA (2,4-dihydroxy-7methoxy-1,4-benzoxazin-3-one, the most abundant benzoxazinoid in maize), are considered to be the most important chemical factors in resistance to leaf-feeding insects, including corn borers such as the European corn borer, Ostrinia nubilalis Hübner, and MCB [6]. Benzoxazinoids are predominantly stored as glucosides in the cell vacuole. Tissue maceration by chewing herbivores results in the release of active aglycones by the action of endogenous $\beta$-glucosidases. Hydroxycinnamates, derived from the phenylpropanoid pathway, comprise another array of compounds that have been extensively studied in relation to their function in constitutive resistance to herbivores [7-9]. Grasses contain relatively high concentrations of ferulates (FAs) and $p$-coumarates ( $p$ CAs) linked to hemicellulose and lignin polymers. The FAs are attached by ester bonds to arabinose side chains of arabinoxylans and can be coupled by oxidative reactions to form dehydrodimers (diferulates, DFAs) that crosslink hemicellulose, or bind lignin monomers via ether bonds that cross-link hemicellulose with lignin. In cereals, $p$ CAs are incorporated into cell walls where they are esterlinked to lignin monolignols, and are thought to function in transferring radicals during the polymerization of lignin $[7,10]$. The constitutive contents of $p$ CAs and FAs in cell walls and the degree of hemicellulose cross-linking by DFA bridges has been suggested to be a structural defense mechanism against insect damage. Several studies reported that differences in cell wall-bound hydroxycinnamate contents in grains, leaves, or stem tissues between resistant and susceptible genotypes of maize, wheat, and tall fescue were associated with contrasting levels of resistance to folivores and stem borers and with reduced insect performance [5, 8, 9, 11-13].

In addition to constitutive resistance, maize shows other responses induced by insect feeding. Khajuria et al. [14] described the up-regulation of various enzymes in the phenylpropanoid metabolic pathway in wheat after infestation by Hessian fly (Mayetiola destructor Say) that led to increased abundance of the phenolics 4-hydroxy- cinnamate and vanillin. Several studies have focused on the induction of benzoxazinoid accumulation in leaves by insect attack. In maize leaves, the transcript levels of $B x 1$, the first gene in the benzoxazinoid biosynthesis pathway, were shown to increase after caterpillar attack $[15,16]$. In parallel, the benzoxazinoid content in maize leaves changed after infestation by specialist and generalist caterpillars; insect feeding led to significant increases in DIMBOA and HDMBOA-Glc (the methylated form of DIMBOA-Glc) and decreased levels of DIMBOA-Glc, and the younger leaves were more prone to benzoxazinoid induction than older ones [15, 17-19]. In relation to MCB attack, Rodriguez et al. [20] showed that maize stalks near the flowering stage responded to MCB attack by activating general plant defense mechanisms, including genes encoding jasmonic acid biosynthetic enzymes, proteinase inhibitors, defense-related transcription factors, and proteins involved in cell-wall reorganization. Concomitantly, after MCB attack, all genotypes showed no significant decreases in DIMBOA content, while some showed significant changes in the levels of specific hydroxycinnamate compounds that were probably involved in cell-wall stiffness. However, the induced response to $\mathrm{MCB}$ at earlier stages of maize development, when maize leaves are damaged by first-generation larvae, has not been studied, and there is no information about the induction of resistance-related metabolites at this stage of development.

Furthermore, little is known about insect and plant metabolites involved in eliciting the response to MCB attack and in perceiving and signaling damage caused by this lepidopteran species. Plants likely use two strategies to optimize their response to herbivore feeding: damaged-self recognition, and herbivore-associated molecular patterns (HAMPs)-based specific responses. However, HAMPs-triggered immunity can be partially suppressed by herbivore-associated effector molecules $[21,22]$. HAMPs have been found in oral secretions such as regurgitant and those of salivary glands. These secretions have been shown to modulate specific defense responses to herbivores, either amplifying or suppressing direct and indirect defenses elicited by wounding [23-27]. HAMPs identified in the regurgitant or saliva of insect species include amino acid-fatty acid conjugates (FACs), enzymes such as $\beta$-glucosidase and glucose oxidase, fragments of ingested plant proteins, sulfated fatty acids, and cell wall fragments [27, 28]. In maize, the regurgitants of Lepidoptera species such as Spodoptera littoralis (Boisduval) and Spodoptera exigua Hübner were shown to induce plants to release volatile compounds and trigger direct responses [15, 29-31]. So far, no studies have determined presence of HAMPs in MCB regurgitant. Identification of such HAMPs is the first step to determine whether MCB regurgitant can promote maize defense 
responses and increase resistance. Similarly, although jasmonic acid has been proposed as an important molecule in mediating the maize response to herbivore attack, little is known about its role as a signaling molecule in the induced response to MCB [32]. Recently, methyl jasmonate (MeJA) was suggested to play an important role in maize defense signaling against Asian corn borer (Ostrinia furnacalis) attack [33].

The overall aim of this study was to expand our knowledge about the factors involved in triggering and signaling the maize response to first-generation MCB attack, to determine if constitutive resistance metabolites respond to first-generation MCB attack, and to assess whether the induced response increases leaf resistance to MCB. The specific objectives were as follows: 1) to determine whether the response to leaf feeding by $\mathrm{MCB}$ larvae increases leaf antibiosis against MCB in two maize genotypes with contrasting levels of resistance against MCB; 2) to determine if MCB regurgitant has a role in eliciting that response; 3 ) to ascertain if MeJA functions in mediating the maize response; and 4) to evaluate the effect of several treatments (feeding by MCB larvae, exposure to MeJA, and application of MCB regurgitant upon wounding) on metabolites that are known to be involved in constitutive resistance to MCB attack.

\section{Results}

\section{Non-choice feeding bioassays}

To evaluate if feeding by MCB increases the antibiosis of leaves in young plants, MCB larvae were reared for 13 days on excised leaves from maize plants previously infested with MCB larvae (48 $\mathrm{h}$ before), and larval weight and survival were monitored. The growth and survival on leaves from plants in other treatments (wounding, application of regurgitant upon wounding, and exposure to MeJA) and untreated plants (control) were monitored at the same time. The regression curves of larval weights with time (growth curves) showed that larvae grew better on leaves from untreated plants than on those from treated plants regardless of the maize genotype (Fig. 1, Additional file 1: Table S1). However, the differences among treatments varied between the two maize genotypes. The antibiosis levels of the leaves from EP39 and EP42 plants pre-infested with MCB larvae were similar at the early stage of the bioassay (6 days after treatment; dat) $(p>0.05)$ (Table 1). Leaves of EP42 had a stronger antibiotic effect on larval weight than those of EP39 at 15 days after wounding, but the opposite effect was observed when leaves were treated with MeJA. The responses to treatments differed slightly between the two maize genotypes; differences among treatments in EP39 became significant at 8 dat, while differences in EP42 became significant at 10 dat. The effect of MeJA treatment was similar to that of infestation treatment in EP42 at 15 dat, while the effect of MeJA treatment was similar to those of the wounding treatment and the regurgitant treatment in EP39. The wounding treatment and the regurgitant treatment negatively affected larval development on both maize genotypes at 15 dat (Table 1).

The larval survival curves differed significantly among treatments when larvae were fed with leaves from EP42 (log-rank test, $p=0.02$ ), but not when they were fed with leaves from EP39 (log-rank test, $p=0.34$ ) (Table 2). Wounding was the only treatment that significantly reduced the survival of larvae fed with EP42 leaves, compared with control plants $(p<0.05)$ (Table 2$)$.

\section{Cell wall bound hydroxycinnamates and DIMBOA concentrations in maize leaves}

Next, we determined whether leaf feeding by MCB larvae, wounding, wounding $+\mathrm{MCB}$ regurgitant, or exposure to MeJA affected cell wall-bound hydroxycinnamates and DIMBOA concentrations in the leaves. The concentrations of $p$ CA, FAs, total DFAs (DFAT), and DIMBOA in the leaves of treated and control plants were compared at 2 and 15 dat. Leaf feeding by MCB larvae resulted in significantly increased contents of cell wall-

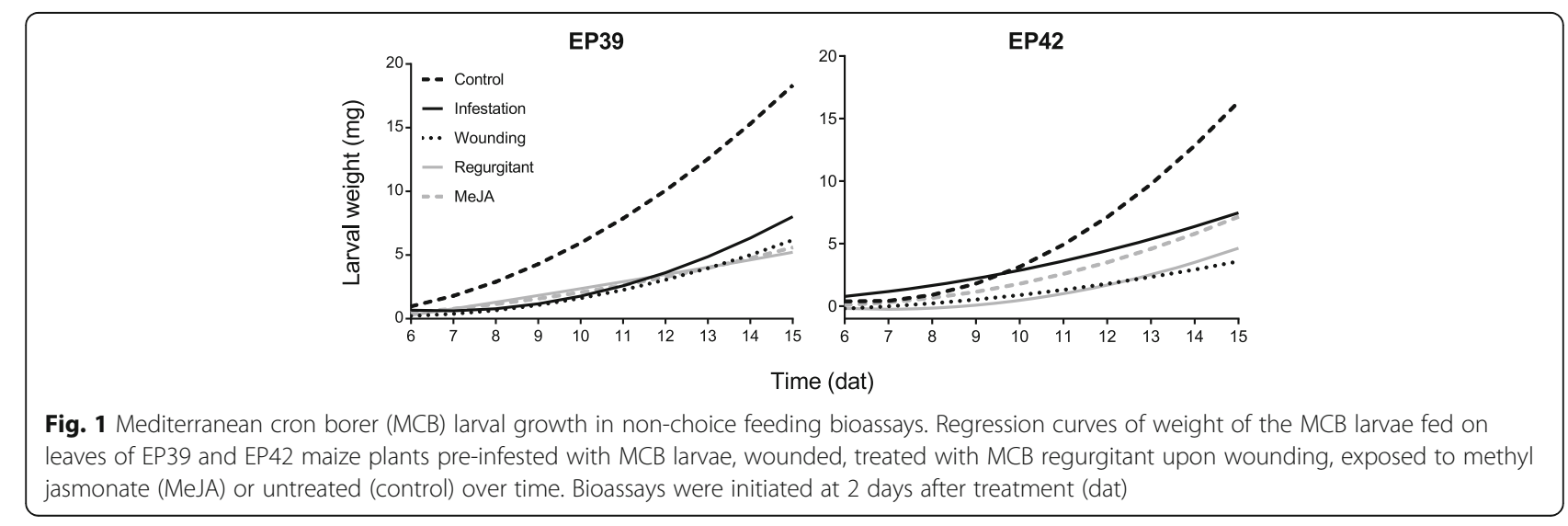


Table 1 Mediterranean corn borer larval weights in non-choice feeding bioassays

\begin{tabular}{|c|c|c|c|c|c|c|c|c|c|c|c|}
\hline \multirow[t]{2}{*}{ Genotype } & \multirow[t]{2}{*}{ Treatment } & \multicolumn{10}{|c|}{ Days of feeding ${ }^{a}$} \\
\hline & & 6 dat & & 8 dat & & $10 \mathrm{da}$ & & 13 dat & & 15 dat & \\
\hline \multirow[t]{5}{*}{ EP39 } & Control & 3.52 & $\mathrm{a}$ & 5.21 & $a$ & 7.97 & $\mathrm{a}$ & 15.51 & $\mathrm{a}$ & 20.46 & a \\
\hline & Infestation & 3.09 & a & 3.71 & $a b$ & 4.02 & $\mathrm{bc}$ & 7.01 & c & 10.49 & $b$ \\
\hline & Wounding & 2.71 & a & 2.90 & $b$ & 3.97 & $\mathrm{bc}$ & 6.66 & $\mathrm{~cd}$ & 8.47 & $\mathrm{bcc}$ \\
\hline & Regurgitant & 2.68 & a & 3.51 & $a b$ & 5.16 & $b$ & 6.30 & cde & 7.78 & cde \\
\hline & MeJA & 2.46 & a & 3.46 & $b$ & 4.00 & bc & 4.54 & e & 7.16 & de \\
\hline \multirow[t]{5}{*}{ EP42 } & Control & 2.68 & a & 4.29 & $a b$ & 5.58 & $b$ & 11.05 & $b$ & 18.96 & a \\
\hline & Infestation & 3.24 & a & 4.28 & $a b$ & 5.37 & $b$ & 7.66 & c & 10.04 & $b$ \\
\hline & Wounding & 2.33 & a & 2.89 & $b$ & 3.07 & c & 4.88 & de & 5.90 & e \\
\hline & Regurgitant & 2.29 & $\mathrm{a}$ & 2.48 & $b$ & 2.93 & c & 4.88 & de & 7.22 & de \\
\hline & MeJA & 2.53 & $\mathrm{a}$ & 3.22 & $\mathrm{~b}$ & 4.32 & bc & 6.82 & $\mathrm{~cd}$ & 9.68 & bc \\
\hline
\end{tabular}

Least square (LS) mean values of larval weight (mg) of MCB larvae fed on leaves from maize plants pre-infested with MCB larvae, wounded, treated with MCB regurgitant upon wounding, exposed to methyl jasmonate (MeJA) or untreated (control). Bioassays were initiated 2 days after treatment (dat)

${ }^{a}$ Within each column, different letters indicate significant differences $(p<0.05)$

bound FAs and DFAT in the leaves of EP39 and EP42 at 2 dat $(p<0.05)$ (compared with control), while the increase in $p$ CAs was only significant in EP39 leaves (Fig. 2a, Additional file 1: Table S2). At 15 dat, the DFAT concentration in leaves infested by MCB was higher than that in leaves of untreated plants, but the difference was only significant for EP39 (Fig. 2b, Additional file 1: Table S2). Interestingly, application of $\mathrm{MCB}$ regurgitant to wounded leaves produced short-term increases (2 dat) in the level of cell wall-bound hydroxycinnamates, similar to those reported after leaf feeding by MCB larvae. In EP42, regurgitant application resulted in higher $p$ CAs, FAs, and DFAT contents in leaves than did wounding alone, although this difference was only significant for DFAT contents $(p<0.05)$ (Fig. 2a, Additional file 1: Table S2). In the long term, wounding and the application of regurgitant had similar effects on hydroxycinnamates content, and those effects were the opposite of those induced by larval feeding (Fig. 2b, Additional file 1: Table S2). Exposure to MeJA produced

Table 2 Mediterranean corn borer larval survival in non-choice feeding bioassays

\begin{tabular}{lcccc}
\hline Treatment & EP39 & & EP42 & \\
\hline Control & -6.94 & $\mathrm{a}$ & -4.16 & $\mathrm{bc}$ \\
Infestation & 2.88 & $\mathrm{a}$ & -1.92 & $\mathrm{abc}$ \\
Wounding & 0.87 & $\mathrm{a}$ & 7.97 & $\mathrm{a}$ \\
Regurgitant & -0.09 & $\mathrm{a}$ & 5.87 & $\mathrm{ab}$ \\
MeJA & 3.28 & $\mathrm{a}$ & -7.77 & $\mathrm{c}$ \\
\hline
\end{tabular}

Values of log-rank statistic for testing homogeneity of survival distribution of MCB when larvae were reared on previously infested, wounded, treated with regurgitant upon wounding, treated with methyl jasmonate (MeJA) and untreated (control) plants. Positive values of log-rank statistic indicate that number of dead larvae is greater than that expected under the null hypothesis of equivalent survival distributions

aLog-rank statistics followed by the same letter in the same row indicate that survival curves were homogeneous $(p>0.05)$ slight increases (not significant) in cell wall-bound hydroxycinnamates contents in the leaves over time (Fig. 2a and b).

We detected DIMBOA in treated and control leaves at 2 dat, and only the MeJA treatment increased the DIMBOA concentration to a level higher than that in the control. The wounding, wounding + regurgitant, and infestation treatments resulted in decreased DIMBOA contents $(p>0.05)$. This opposite changes in DIMBOA contents between infested/wounded plants and MeJAtreated plants resulted in significantly different concentrations of DIMBOA in EP39 plants $(p<0.05)$ (Fig. 2a, Additional file 1: Table S2). No DIMBOA was detected in the treated leaves at 15 dat, and the DIMBOA content in leaves of untreated plants was 3-fold higher in EP39 $(1041.72 \mu \mathrm{g} / \mathrm{g})$ than in EP42 $(303.65 \mu \mathrm{g} / \mathrm{g})(p<0.05)$ (Fig. 2b, Additional file 1: Table S2).

\section{Discussion}

Insect attack induces defense mechanisms in plants that can reduce the fitness of the herbivorous insect. In maize, negative effects on the growth of larvae fed on leaves previously exposed to insect feeding or insect elicitors has been reported for noctuid species such as $S$. littoralis and Spodoptera frugiperda [15, 29, 34], and for the crambid O. nubilalis [26]. In this study, the effect of leaf feeding by MCB on the suitability of leaves for MCB growth was assessed for 13 days (from 2 dat to 15 dat) in two maize genotypes. We found that MCB larvae grow slower on leaves from previously infested plants, regardless of the maize genotype. The antibiotic effect triggered in leaves by insect feeding was only relevant in the long term, because differences in larval weights between those reared on untreated and previously infested plants became significant only after 8 days of feeding. These results highlight the relevance of performing long-term bioassays, because the antibiosis 


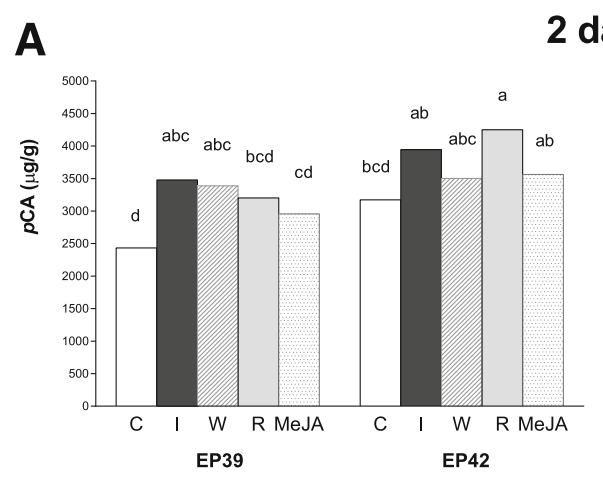

\section{2 dat}
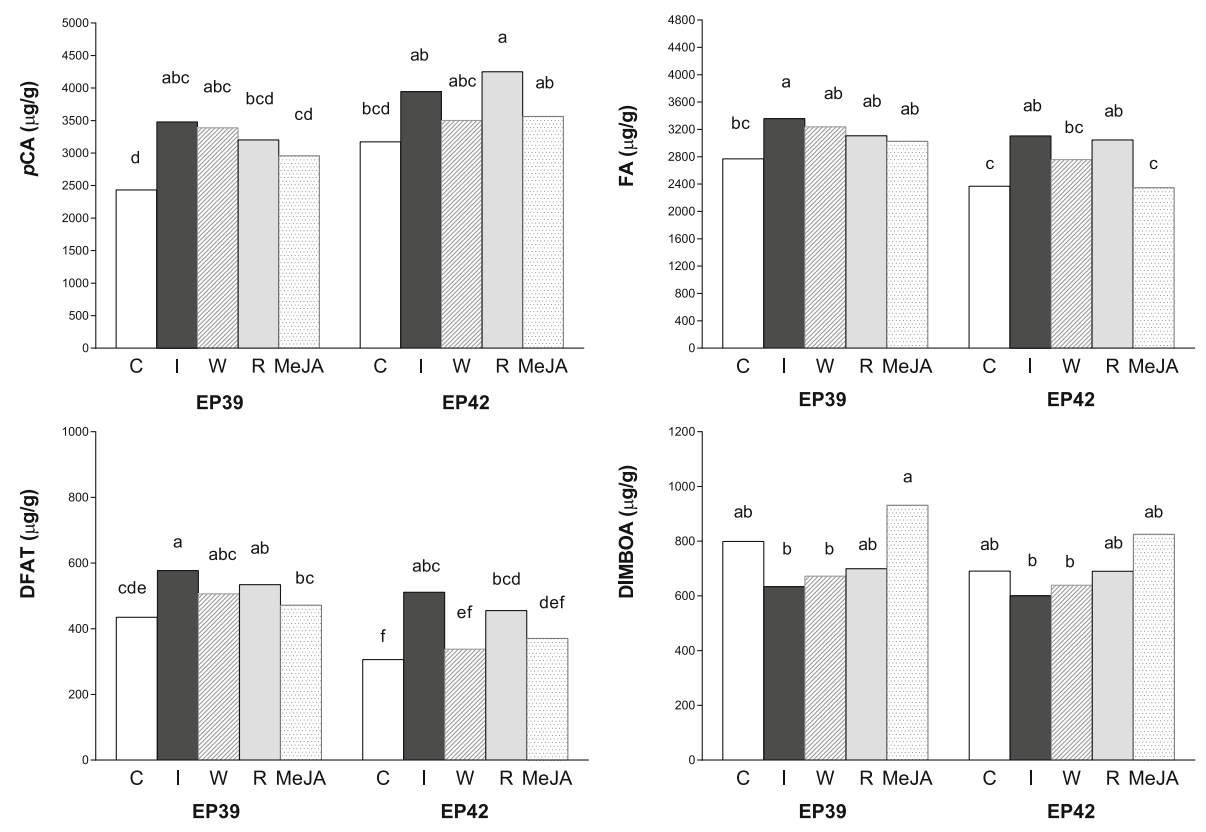

B

15 dat
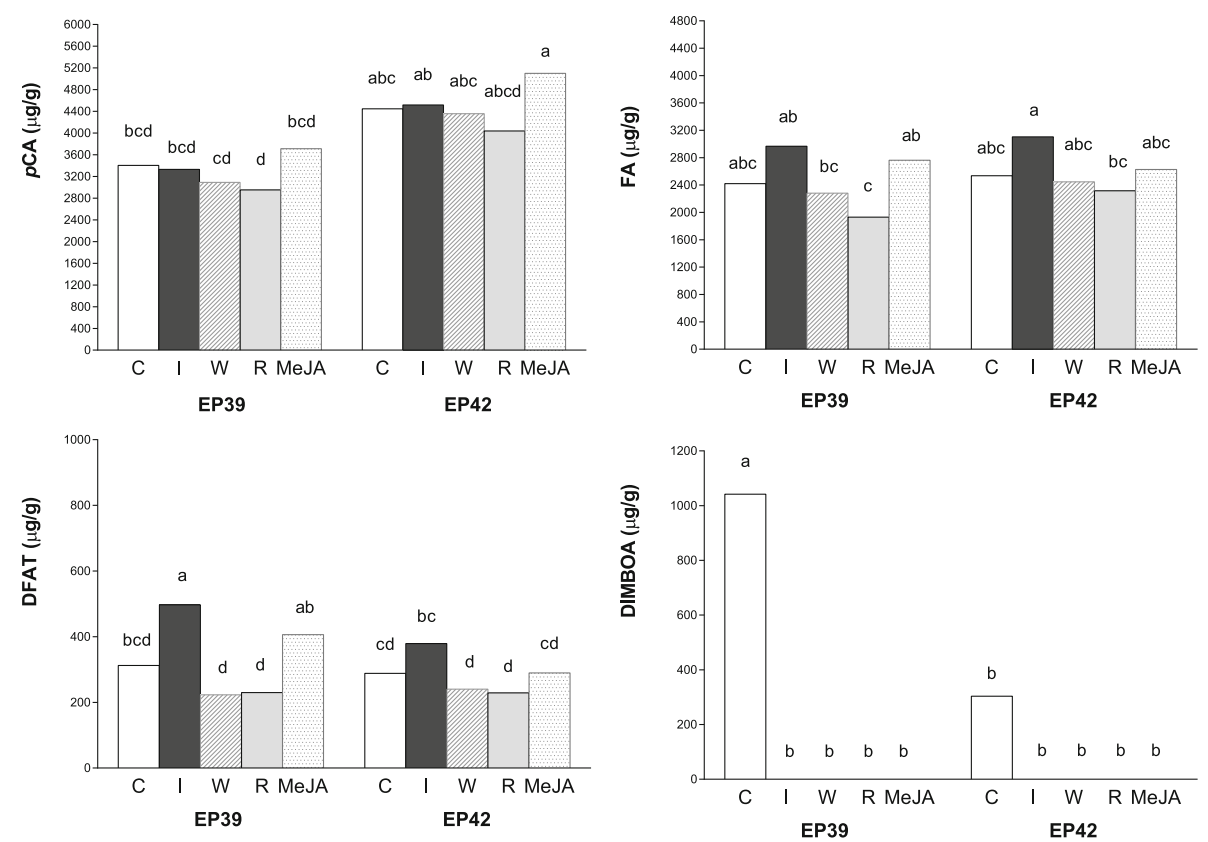

Fig. 2 Cell wall-bound hydroxycinnamate and 2,4-dihydroxy-7-methoxy-1,4-benzoxazin-3-one (DIMBOA) concentrations in maize leaves. Mean concentration of cell wall bound hydroxycinnamates and DIMBOA ( $\mu \mathrm{g} / \mathrm{g}$ dry weight) in the leaves of maize inbreds EP39 and EP42 at 2 (a) and 15 (b) days after (dat) infestation with Mediterranean corn borer (MCB) larvae (I), wounding (W), wounding + MCB regurgitant application (R), methyl jasmonate exposure (MeJA), and no treatment (C). pCA, p-coumarate; FA, ferulate; DFAT, total diferulates

effect could be exponential rather than linear, and/or plant responses to short and long-term infestation could differ due to continuous cross-talk between the plant and the larvae. The plant response triggered by the first contact with the insect may differ from that induced later, so that the metabolic arsenal of the larvae may be modified as a counter-response to plant induction. The EP39 response to infestation seemed to contribute earlier than that of EP42 to leaf antibiosis. However, at the end of bioassay, the antibiosis levels of EP42 and EP39 
leaves from infested plants were similar. Studies on other chewing herbivores have shown that leaf feeding can increase plant resistance, which can be measured as reduced larval growth. However, this effect depends on the insect species, plant genotype, and the interval between priming and evaluating antibiosis [35, 36]. We conclude that leaf feeding increased resistance to $\mathrm{MCB}$ in two different maize genotypes, but the response to $\mathrm{MCB}$ attack was not immediate.

The application of MCB regurgitant upon wounding did not significantly increase the antibiosis of maize leaves more than mechanical wounding alone, because the plant responses elicited by MCB regurgitant + wounding and wounding alone retarded larval growth to the same extent. Therefore, MCB regurgitant does not appear to play an important role in eliciting direct defenses. Alternatively, the procedure used to apply the regurgitant may need improvement, because the regurgitant was applied once, rather than multiple times over time, which would more closely mimic possible regurgitant secretion during feeding. Also, because the response of maize plants to insect regurgitant depends on plant age, time of exposure, and maize genotype [31, 34, 37], we cannot rule out that regurgitant from $\mathrm{MCB}$ larvae could play a crucial role in inducing maize defense mechanisms at other plant stages and/or in maize genotypes different from those studied here. Regurgitant from pests such as S. exigua, S. littoralis, and Mythimna separata (Walker) was shown to induce defense-related genes and jasmonic acid accumulation $[15,29-31,38]$, but regurgitant from other corn borers present in Europe, such as the European corn borer $(O$. nubilalis), did not elicit direct defenses in maize leaves [26]. In this last case, it was the saliva from O. nubilalis, and not the regurgitant, that was the critical component for inducing direct plant defenses in maize [26].

The results of the bioassay indicated that HAMPs were not present in MCB regurgitant, but suggested that herbivore-associated effector molecules could be present in some other $\mathrm{MCB}$ secretions because the wounding and $\mathrm{MCB}$ regurgitant + wounding treatments resulted in lower larvae growth than did actual herbivory. This could indicate that $\mathrm{MCB}$ larvae partially counteract plants' responses to mechanical damage, making the infested leaves less harmful for consumption than mechanically wounded leaves. Salivary and frass effectors in other Lepidoptera species that disrupt plant defense signaling are currently being studied [27, 39-41]. In addition, we speculate that the possible effectors present in MCB frass or saliva could suppress some of the maize defenses against MCB attack mediated by jasmonic acid, as reported for the maize-S. frugiperda interaction [40]. However, this partial suppression of defenses would depend on the maize genotype, because MeJA and infestation treatments had similar effects on the antibiosis of
EP42 leaves, but MeJA and wounding treatments had similar effects on the antibiosis of EP39 leaves. In EP39, the combination of MeJA + wounding reduced larval growth more than did the infestation treatment.

After investigating the effects of plant treatments (infestation, MCB regurgitant + wounding, and exposure to MeJA) on MCB growth and survival, we determined whether these treatments induced the accumulation of resistance-related compounds (DIMBOA and cell wallbound hydroxycinnamates) in leaves. At 2 dat, maize plants in all treatments and both genotypes had DIMBOA levels ranging from 600 to $932 \mu \mathrm{g} / \mathrm{g}$ dry weight. However, at 15 dat, no DIMBOA was detected in treated plants; while the concentration in untreated EP39 and EP42 plants was 1042 and 304 $\mu \mathrm{g} / \mathrm{g}$ dry weight, respectively. Several studies have reported that HDMBOA-Glc was strongly induced in maize soon (24-48 h) after herbivory or jasmonic acid elicitation, while DIMBOA-Glc levels decreased $[17,18,39]$. We propose that longer term (15 dat) tissue disruption and exposure to MeJA could result in total conversion of DIMBOA-Glc to HDMBOA-Glc to better deter herbivory by specialist insects, because HDMBOA, unlike DIMBOA, cannot be detoxified by insects via glycosylation [19]. At this stage of development and using the current methodology, the only peak at quantifiable concentrations was that corresponding to DIMBOA. Further in-depth research using precise analytical procedures needs to be carried out to identify and quantify the presence of derivates at lower concentrations.

We also investigated whether induced cell wall fortification mediated by hydroxycinnamates occurs in maize leaves after MCB attack, and tested whether MCB regurgitant and jasmonic acid play roles in elicitation and signaling. Maize plants infested with MCB larvae showed increased cell wall FAs and DFAT contents in leaves at all sampling times, suggesting that leaf feeding by MCB larvae modified the leaf cell wall structure by increasing feruloylation of arabinoxylan chains and favoring hemicellulose cross-linking. Changes in hydroxycinnamate contents in maize stalk after $\mathrm{MCB}$ attack have been reported previously [20]. In the short term, the effects of MCB regurgitant + wounding on FAs and DFAT contents were similar to the effect of larval feeding, but a significant effect of MCB regurgitant + wounding on FA and DFAT contents was detected at 15 dat. Therefore, the continuous contact of the maize plant with regurgitant elicitors during larval feeding may have a role in maintaining higher rates of FAs and DFAT synthesis in infested vs. control plants. Unlike regurgitant + wounding and infestation treatments, MeJA and wounding treatments did not cause a significant difference in DFAT compared with that in the control at 2 dat. This result suggested that the response mediated by jasmonic acid 
signaling or mechanical damage cannot solely explain the changes in FAs and DFAT contents in the infested plants. Cell wall $p$ CAs were induced after infestation but, unlike FAs and DFAT, the $p$ CAs levels were similar in infested and control plants at 15 dat. Therefore, although cell wall $p$ CAs are related to lignin deposition and their abundance is positively correlated with lignin content in several plant species $[7,9,42]$, they did not seem to participate in longterm leaf cell wall fortification in maize induced by $\mathrm{MCB}$ attack.

Increased feruloylation and polymer cross-linking by insect feeding could reinforce the leaf cell wall. This reinforcement is expected to hinder the activity of cell wall-degrading enzymes and affect the accessibility and digestibility of plant tissues, and hence, larval performance $[8,43]$. Nevertheless, after infestation, the significant difference in hydroxycinnamate contents between genotypes (higher in EP39 than in EP42) at 15 dat was not associated with a significant difference in antibiosis against MCB. Therefore, other mechanisms induced by insect attack, besides hydroxycinnamate induction and DIMBOA metabolism, could be involved in reducing insect performance on leaves of EP42.

\section{Conclusions}

In both maize genotypes, the leaf responses to MCB infestation retarded the growth of MCB larvae but barely affected larval survival. In maize, MCB regurgitant could play a role in inducing DFAT accumulation, but herbivore-associated effector molecules that suppress some responses triggered by wounding could also be involved in the maize-MCB interaction. In the EP39 maize line, the plants strengthened their leaf cell walls through incorporating hydroxycinnamates and increasing hemicellulose cross-linking in response to MCB attack, while the induced defenses in the EP42 line appeared to reflect a wider array of resistance mechanisms.

\section{Methods}

\section{Insect rearing and regurgitant collection}

The MCB larvae were obtained from the colony maintained at the insectary of the Misión Biológica de Galicia-CSIC (Spanish National Research Council). Second instar larvae (weight, 1-2 $\mathrm{mg}$ and approximately $5 \mathrm{~mm}$ body size) were fed on a maize-based artificial diet and then starved for $24 \mathrm{~h}$ before artificial infestation, growth, and survival bioassays. The $\mathrm{MCB}$ regurgitant was collected from $4^{\text {th }}-5^{\text {th }}$ instar larvae previously fed on maize stem tissue for at least $48 \mathrm{~h}$. Larvae were chilled on ice and immobilized. As larvae returned to room temperature they were squeezed until the regurgitant was expelled. Regurgitant from 50 larvae $(300 \mu \mathrm{l}$ approx.) was mixed with $150 \mu \mathrm{l} 0.1 \mathrm{M}$ phosphate buffer solution (PBS) and frozen. This mixture was applied to plants immediately after wounding as described below.

\section{Plant materials and treatment applications}

Two different maize inbred lines (EP39 and EP42, both European flint lines) were used in this study. In previous studies, these two lines showed different gene ontology (GO) categories involved in the response to stem tunneling by MCB larvae [20], contrasting resistance to stem borer, and different cell wall hydroxycinnamate composition of pith tissues $[3,5,44-46]$. Maize plants were individually grown in pots in greenhouse conditions and arranged in a split-plot design, where treatments were assigned to the main plots and maize genotypes were assigned to sub-plots. Twenty plants for each treatment-genotype combination were planted. Five treatments were applied to maize plants at the V6-V8 stage (six to eight fully expanded leaves): infestation with MCB larvae, wounding, wounding + MCB regurgitant; exposure to MeJA; and control (untreated plants). In the infestation treatment, three $2^{\text {nd }}$ instar larvae were placed in the whorl of the maize plants and were allowed to feed freely. The pots were protected with nets to avoid larvae dispersion. In the wounding + MCB regurgitant treatment, three leaf wounds (scratches) of $5 \times 5 \mathrm{~mm}$ were made with a scalpel on each plant, and $5 \mu \mathrm{l}$ regurgitant mixture was applied to each wound using a micropipette. The total amount of regurgitant mixture applied to each plant was $15 \mu \mathrm{l}$ (containing regurgitant from approximately 5 larvae). In the wounding treatment, wounding was conducted as described above and $5 \mu \mathrm{l}$ PBS solution $(15 \mu \mathrm{l}$ PBS per plant) was applied to each wound. In a fourth treatment, plants were exposed to exogenous MeJA, a known elicitor of the defense response, by placing a cotton tip soaked with $100 \mu \mathrm{M}$ MeJA dissolved in ethanol $(10 \% \mathrm{v} / \mathrm{v})$ in a leaf axil. Leaves from different plants of each treatment-genotype combination were collected for the non-choice feeding bioassay with $\mathrm{MCB}$ larvae, biochemical analyses, and RNA quantification.

\section{Non-choice feeding bioassays}

The non-choice feeding assay was used to assess the effects of various plant treatments on the subsequent development and survival of MCB larvae reared on leaves from pre-conditioned plants. Two days after treatments were applied, $2^{\text {nd }}$ instar $\mathrm{MCB}$ larvae were initially weighed and placed in multi-well plates on fresh leaf discs. Twenty larvae per treatment and genotype were tested in duplicate (i.e., $n=80$ larvae per treatment) and were maintained in a growth chamber under controlled temperature and humidity conditions $\left(22{ }^{\circ} \mathrm{C}, 80 \% \mathrm{RH}\right)$ under a 16 L:8D photoperiod. Every $2-3$ days, new fresh leaf discs were provided to the larvae. Larval weights 
and data related to dead and missing larvae were recorded at $6,8,10,13$, and 15 dat.

A repeated-measure analysis was performed to test differences for larval weights using the PROC MIXED procedure of SAS software (SAS Institute, Inc., Cary, NC, USA) $[47,48]$. Initial larval weight was included as a covariate, genotype was set as a random factor, and a firstorder autoregressive covariance structure (AR-1) was chosen in the within-subject correlation. The initial larval weight was subtracted from the larval weight at each time point in each treatment and genotype, and values shown are least square (LS) means. Linear and quadratic coefficients for the regression of larval weight over time were obtained for each treatment-genotype combination. Within each genotype, larval growth curves were compared between pairs of treatments by making orthogonal contrasts between the two treatments' regression parameters (intercept, linear, and quadratic components $)(p \leq 0.05)[48,49]$. The PROC LIFETEST procedure of SAS was used to test differences in larval survival among treatments within the same genotype using the Kaplan-Meier method [47]. The death of larvae was an important event, and numbers of missing and alive larvae at the end of the bioassay were recorded. The homogeneity of survival distribution was tested using the log-rank test $(p \leq 0.05)$.

\section{Quantification of cell wall bound hydroxycinnamates and benzoxazinoids}

For each genotype-treatment combination, leaves from four and two plants were collected at 2 and 15 days after treatment (dat), respectively, frozen $\left(-20^{\circ} \mathrm{C}\right)$, and then lyophilized. Cell wall-bound hydroxycinnamates were extracted from 500-mg ground leaf samples (two replicates), as described previously [46]. Briefly, samples were extracted in $80 \%$ methanol for $1 \mathrm{~h}$ and then centrifuged. The pellet was shaken in $2 \mathrm{~N} \mathrm{NaOH}$ under nitrogen for $4 \mathrm{~h}$. Digested samples were neutralized with $6 \mathrm{~N} \mathrm{HCl}$ and the $\mathrm{pH}$ was lowered to 2.0. After centrifugation, the supernatant was collected and the pellet was washed twice with distilled water. Supernatants were pooled and then extracted twice with ethyl acetate. Collected organic fractions were combined and reduced to dryness using a Savant Speed Vac (Savant Instruments, Holbrook, NY, USA). The final extract was dissolved in $1.5 \mathrm{ml}$ methanol, filtered through a $20-\mu \mathrm{m}$ pore tetrafluoroethylene filter, and stored at $-20{ }^{\circ} \mathrm{C}$. For DIMBOA analysis, 100-mg ground leaf samples were extracted in $5 \mathrm{ml} \mathrm{HPLC}$-grade methanol and $50 \mu \mathrm{l}$ acetic acid. The mixture was vortexed and then incubated in a sonicator water bath for $60 \mathrm{~min}$ at $60{ }^{\circ} \mathrm{C}$. The supernatant $(0.5 \mathrm{ml})$ was combined with $0.5 \mathrm{ml}$ distilled water in a microcentrifuge tube, vortexed, and centrifuged for $5 \mathrm{~min}$ at $1000 \times \mathrm{g}$. The supernatants were transferred into vials and stored.
The HPLC analyses were performed using a 2690 Waters Separation Module (Waters, Milford, MA, USA) equipped with a 996 Photodiode Array Detector (Waters) with a YMC ODS-AM (Waters) narrow bore column $(100 \times 2 \mathrm{~mm}$ i.d.; $3 \mu \mathrm{m}$ particle size). For elution, the mobile phase consisted of acetonitrile (solvent A) and trifluoroacetic acid (0.05\%) in water (solvent B) delivered under the following gradient conditions: initial A:B ratio of 10:90, changing to $30: 70$ in $3.5 \mathrm{~min}$, then to $32: 68$ in $6.5 \mathrm{~min}$, then to $100: 0$ in $4 \mathrm{~min}$, then isocratic elution with 100:0 for $4.5 \mathrm{~min}$, and finally returning to initial conditions after $3 \mathrm{~min}$. The flow rate was $0.3 \mathrm{ml} / \mathrm{min}$. The sample injection volume was $4 \mu \mathrm{l}$, and the elution profiles were monitored by UV absorbance at 325 and $254 \mathrm{~nm}$. Retention times and UV spectra were compared with those of freshly prepared standard solutions ( $p$ CA, FA, 5-5-DFA, and DIMBOA). P-Coumaric and ferulic acids obtained from Sigma (St. Louis, MO, USA), 5-5' DFA was synthesized by the group of $\mathrm{N}$. Towers (University of British Columbia, Vancouver, Canada), and DIMBOA was provided by the group of C. Souto (University of Vigo, Pontevedra, Spain). The UV spectra of other DFAs were compared with previously published spectra [50]. We identified and quantified four isomers of DFA: 5-5'DFA, 8-5'DFA (sum of 8-5'-non-cyclic and 8-5'-benzofuran forms), and 8$\mathrm{o}-4$ 'DFA. The sum of these isomers represented the total DFA (DFAT) content. The results are expressed as $\mu \mathrm{g} / \mathrm{g}$ dry weight. Combined analyses of variance (ANOVA) for each compound concentration at each sampling time (2 and 15 dat) were performed with the GLM procedure of SAS, and all factors, except replicates, were considered fixed. Differences in compound contents between genotypes within each treatment were tested by comparing LS means $(p \leq 0.05)$.

\section{Additional files}

Additional file 1: Supplementary Tables. Table S1. Estimates of parameters for regression of MCB larval weight over time; Table S2. Cell wall-bound hydroxycinnamates and 2,4-dihydroxy-7-methoxy-1,4-benzoxazin-3-one (DIMBOA) concentrations in maize leaves. (DOCX $23 \mathrm{~kb}$ )

Additional file 2: Bioassays raw data. (XLSX 33 kb)

\section{Abbreviations}

Dat: days after treatment; DFA: Diferulates; DFAT: Total diferulates; DIMBOA: 2,4-dihydroxy-7-methoxy-1,4-benzoxazin-3-one; FA: Ferulates; HAMPs: Herbivore-associated molecular patterns; MCB: Mediterranean corn borer (Sesamia nonagrioides); MeJA: Methyl jasmonate; $p C A$ : $p$-coumarates

\section{Acknowledgements}

We thank Ana Alonso for assistance with larvae rearing and Ana Carballeda for help with laboratory analyses.

\section{Funding}

This research was supported by the National Plan for Research and Development of Spain (AGL2012-33415, AGL2015-67313-C2-1-R, and AGL2015-67313-C2-2-R) co-financed by the European Social Fund (FEDER). R. Santiago acknowledges postdoctoral contract "Ramón y Cajal" financed by the Ministry of Economy and Competitiveness (Spain), Vigo University, and the European Social Fund. 


\section{Availability of data and materials}

Data from the bioassays are available as Additional file 2 .

\section{Authors' contributions}

$\mathrm{RS}$ and $\mathrm{RM}$ designed the experiments. $\mathrm{RS}, \mathrm{AC}$, and $\mathrm{AB}$ wrote the manuscript, performed experiments and analyzed and evaluated the data. AL helped with experiments. VM and AB performed some statistical analyses. GS and RM critically revised the manuscript. All authors have read and approved the manuscript.

\section{Competing interests}

The authors declare that they have no competing interests.

\section{Consent for publication}

Not applicable.

\section{Ethics approval and consent to participate}

Not applicable.

\begin{abstract}
Author details
'Universidad de Vigo, Agrobiología Ambiental Calidad de Suelos \& Plantas UVIGO, Unidad Asociada MBG CSIC, Vigo 36310, Spain. ${ }^{2}$ Misión Biológica de Galicia CSIC, Apartado 28, Pontevedra 36080, Spain. ${ }^{3}$ The Genome Center and Department Plant Sciences, University of California, Davis - USDA-ARS. 1636 E. Alisal St., Salinas, CA 93905, USA. ${ }^{4}$ Dept. Biología Vegetal \& Ciencias Suelo, Facultad de Biología, Campus Lagoas Marcosende, Vigo 36310, Spain.
\end{abstract}

Received: 18 October 2016 Accepted: 31 January 2017

Published online: 15 February 2017

\section{References}

1. Cordero A, Malvar RA, Butrón A, Revilla P, Velasco P, Ordás A. Population dynamics and life-cycle of corn borers in south Atlantic European coast. Maydica. 1998:43:5-12.

2. Velasco P, Revilla P, Monetti L, Butrón A, Ordás A, Malvar RA. Corn borers (Lepidoptera: Noctuidae; Crambidae) in Northwestern Spain: Population dynamics and distribution. Maydica. 2007;52:195-203.

3. Santiago R, Butrón A, Reid LM, Arnason JT, Sandoya G, Souto XC, Malvar RA. Diferulate content of maize sheaths is associated with resistance to the Mediterranean corn borer Sesamia nonagrioides (Lepidoptera: Noctuidae). J Agric Food Chem. 2006;54:9140-4.

4. Ortego F, Ruiz M, Castañera P. Effect of DIMBOA on growth and digestive physiology of Sesamia nonagrioides (Lepidoptera: Noctuidae) larvae. J Insect Physiol. 1998:44:95-101.

5. Barros-Rios J, Santiago R, Jung HJG, Malvar RA. Covalent cross-linking of cellwall polysaccharides through esterified diferulates as a maize resistance mechanism against corn borers. J Agric Food Chem. 2015;63:2206-14

6. Niemeyer HM. Hydroxamic acids derived from 2-hydroxy-2H-1,4-benzoxazin-3(4H)one: Key defense chemicals of cereals. J Agric Food Chem. 2009;57:1677-96.

7. Hatfield RD, Marita JM. Enzymatic processes involved in the incorporation of hydroxycinnamates into grass cell walls. Phytochem Rev. 2010:9:35-45.

8. De O Buanafina MM, Fescemyer HW. Modification of esterified cell wall phenolics increases vulnerability of tall fescue to herbivory by the fall armyworm. Planta. 2012;236:513-23.

9. Santiago R, Barros-Rios J, Malvar RA. Impact of cell wall composition on maize resistance to pests and diseases. Int J Mol Sci. 2013:14:6960-80.

10. Grabber JH, Ralph J, Lapierre C, Barrière Y. Genetic and molecular basis of grass cell-wall degradability. I. Lignin-cell wall matrix interactions. C R Biol. 2004;327:455-65

11. Bergvinson DJ, Arnason JT, Hamilton RI. Phytochemical changes during recurrent selection for resistance to the European corn borer. Crop Sci. 1997;37:1567-72

12. García-Lara S, Bergvinson D, Burt AJ, Ramputh Al, Díaz-Pontones DM, Arnason JT. The role of pericarp cell wall components in maize weevil resistance. Crop Sci. 2004:44:1546-52.

13. Barros-Rios J, Malvar RA, Jung HJG, Santiago R. Cell wall composition as a maize defense mechanism against corn borers. Phytochem. 2011;72:365-71.

14. Khajuria C, Wang H, Liu X, Wheeler S, Reese JC, El Bouhssini M, Whitworth RJ, Chen MS. Mobilization of lipids and fortification of cell wall and cuticle are important in host defense against Hessian fly. BMC Genomics. 2013;14:1-16.
15. Erb M, Flors V, Karlen D, De Lange E, Planchamp C, D'Alessandro M, Turlings TCJ, Ton J. Signal signature of aboveground-induced resistance upon belowground herbivory in maize. Plant J. 2009;59:292-302.

16. Tzin V, Lindsay PL, Christensen SA, Meihls LN, Blue LB, Jander G. Genetic mapping shows intraspecific variation and transgressive segregation for caterpillar-induced aphid resistance in maize. Mol Ecol. 2015;24:5739-50.

17. Oikawa A, Ishihara A, Tanaka C, Mori N, Tsuda M, Iwamura H. Accumulation of $\mathrm{HDMBOA}-\mathrm{Gl}$ is induced by biotic stresses prior to the release of MBOA in maize leaves. Phytochem. 2004;65:2995-3001.

18. Köhler A, Maag D, Veyrat N, Glauser G, Wolfender JL, Turlings TCJ, Erb M. Within-plant distribution of 1,4-benzoxazin-3-ones contributes to herbivore niche differentiation in maize. Plant Cell Environ. 2015;38:1081-93.

19. Glauser G, Marti G, Villard N, Doyen GA, Wolfender JL, Turlings TCJ, Erb M. Induction and detoxification of maize 1,4-benzoxazin-3-ones by insect herbivores. Plant J. 2011:68:901-11.

20. Rodríguez VM, Santiago R, Malvar RA, Butrón A. Inducible maize defense mechanisms against the corn borer Sesamia nonagrioides: A transcriptome and biochemical approach. Mol Plant Microbe Interact. 2012;25:61-8.

21. Heil M, Ibarra-Laclette E, Adame-Álvarez RM, Martínez O, Ramirez-Chávez E, Molina-Torres J. How plants sense wounds: damaged-self recognition is based on plant-derived elicitors and induces octadecanoid signaling. PLoS One. 2012;7:e30537. doi:10.1371/journal.pone.0030537.

22. Chung SH, Rosa C, Scully ED, Peiffer M, Tooker JF, Hoover K, Luthe DS, Felton GW. Herbivore exploits orally secreted bacteria to suppress plant defenses. PNAS. 2013;110:15728-33.

23. Felton GW. Caterpillar secretions and induced plant responses. In: Schaller A, editor. Induced plant resistance to herbivory. Netherlands: Springer; 2008 p. $369-87$

24. Consales F, Schweizer F, Erb M, Gouhier-Darimont C, Bodenhausen N, Bruessow F, Sobhy I, Reymond P. Insect oral secretions suppress woundinduced responses in Arabidopsis. J Exp Bot. 2011;63:727-37.

25. Musser RO, Hum-Musser SM, Eichenseer H, Peiffer M, Ervin G, Murphy JB, Felton GW. Herbivory: Caterpillar saliva beats plant defences. Nature. 2002;416:599-600.

26. Louis J, Peiffer M, Ray S, Luthe DS, Felton GW. Host-specific salivary elicitor(s) of European corn borer induce defenses in tomato and maize. New Phytol. 2013:199:66-73.

27. Felton GW, Chung SH, Hernandez MGE, Louis J, Peiffer M, Tian D. Herbivore oral secretions are the first line of protection against plant-induced defences. In: Annual Plant Reviews. West Sussex: Wiley; 2014. p. 37-76.

28. Bonaventure G, VanDoorn A, Baldwin IT. Herbivore-associated elicitors: FAC signaling and metabolism. Trends Plant Sci. 2011;16:294-9.

29. Ton J, D'Alessandro M, Jourdie V, Jakab G, Karlen D, Held M, Mauch-Mani B, Turlings TCJ. Priming by airborne signals boosts direct and indirect resistance in maize. Plant J. 2007:49:16-26.

30. Engelberth J, Seidl-Adams I, Schultz JC, Tumlinson JH. Insect elicitors and exposure to green leafy volatiles differentially upregulate major octadecanoids and transcripts of 12-Oxo phytodienoic acid reductases in Zea mays. Mol Plant Microbe Interact. 2007;20:707-16.

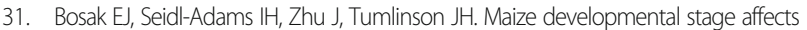
indirect and direct defense expression. Environ Entomol. 2013;42:1309-21.

32. Schmelz EA, Alborn HT, Tumlinson JH. Synergistic interactions between volicitin, jasmonic acid and ethylene mediate insect-induced volatile emission in Zea mays. Physiol Plant. 2003:117:403-12.

33. Yang F, Zhang Y, Huang Q, Yin G, Pennerman KK, Yu J, Liu Z, Li D, Yang AG. Analysis of key genes of jasmonic acid mediated signal pathway for defense against insect damages by comparative transcriptome sequencing. Sci Rep. 2015; 5:16500.

34. Chuang WP, Ray S, Acevedo FE, Peiffer M, Felton GW, Luthe DS. Herbivore cues from the fall armyworm (Spodoptera frugiperda) larvae trigger direct defenses in maize. Mol Plant Microbe Interact. 2014:27:461-70.

35. Agrawal AA. Induced responses to herbivory in wild radish: effects on several herbivores and plant fitness. Ecology. 1999;80:1713-23.

36. Stout MJ, Riggio MR, Yang Y. Direct induced resistance in Oryza sativa to Spodoptera frugiperda. Environ Entomol. 2009:38:1174-81.

37. Degen T, Dillmann C, Marion-Poll F, Turlings TC. High genetic variability of herbivore-induced volatile emission within a broad range of maize inbred lines. Plant Physiol. 2004;135:1928-38.

38. Qi J, Sun G, Wang L, Zhao C, Hettenhausen C, Schuman MC, Baldwin IT, Li J, Song J, Liu Z, Xu G, et al. Oral secretions from Mythimna separata insects specifically induce defense responses in maize as revealed by highdimensional biological data. Plant Cell Environ. 2016. doi:10.1111/pce.12735. 
39. Dafoe NJ, Thomas JD, Shirk PD, Legaspi ME, Vaughan MM, Huffaker A, Teal PE, Schmelz EA. European corn borer (Ostrinia nubilalis) induced responses enhance susceptibility in maize. PLoS One. 2013;8:e73394.

40. Ray S, Gaffor I, Acevedo FE, Helms A, Chuang WP, Tooker J, Felton GW, Luthe DS. Maize plants recognize herbivore-associated cues from caterpillar frass. J Chem Ecol. 2015;41:781-92.

41. Ray S, Alves PCMS, Ahmad I, Gaffoor I, Acevedo FE, Peiffer M, Jin S, Han Y, Shakeel S, Felton GW, Luthe DS. Turnabout is fair play: herbivory-induced plant chitinases excreted in fall armyworm frass suppress herbivore defenses in maize. Plant Physiol. 2016;171:694-706.

42. Scobbie L, Russell W, Provan GJ, Chesson A. The newly extended maize internode: A model for the study of secondary cell wall formation and consequences for digestibility. J Sci Food Agric. 1993;61:217-25.

43. Howe $G$, Schaller A. Direct Defenses in plants and their induction by wounding and insect herbivores. In: Schaller A, editor. Induced plant resistance to herbivory. Netherlands: Springer; 2008. p. 7-29.

44. Butrón A, Malvar RA, Cartea ME, Ordás A, Velasco P. Resistance of maize inbreds to pink stem borer. Crop Sci. 1999;39:102-7.

45. Ordás B, Butrón A, Soengas P, Ordás A, Malvar RA. Antibiosis of the pith maize to Sesamia nonagrioides (Lepidoptera: Noctuidae). J Econ Entomol. 2002;95:1044-8.

46. Santiago R, Butron A, Arnason JT, Reid LM, Souto XC, Malvar RA. Putative role of pith cell wall phenylpropanoids in Sesamia nonagrioides (Lepidoptera: Noctuidae) Resistance. J Agric Food Chem. 2006:54:2274-9.

47. SAS Institute Inc. SAS/STAT ${ }^{\oplus} 9.2$ User's Guide. Cary: SAS Institute Inc; 2008.

48. Littell RC, Milliken GA, Stroup WW, Wolfinger RD, Schabenberger O. SAS for Mixed Models. 2nd ed. Cary: SAS Institute Inc; 2006

49. Littell RC, Milliken GA, Stroup WW, Wolfinger RD. SAS for Mixed Models. Cary: SAS Institute Inc; 1996.

50. Waldron KW, Parr AJ, Ng A, Ralph J, Williamson G. Cell wall esterified phenolic dimers: Identification and quantification by reversed phase high performance liquid chromatography and diode array detection. Phytochem Anal. 1996:7:305-12

\section{Submit your next manuscript to BioMed Central and we will help you at every step:}

- We accept pre-submission inquiries

- Our selector tool helps you to find the most relevant journal

- We provide round the clock customer support

- Convenient online submission

- Thorough peer review

- Inclusion in PubMed and all major indexing services

- Maximum visibility for your research

Submit your manuscript at www.biomedcentral.com/submit

) Biomed Central 